\title{
Right Management and Flushing
}

\author{
Caroline Cullinane
}

\begin{abstract}
Peripheral and central vascular access devices are a fundamental and essential part of healthcare delivery, used extensively in hospital and community settings to meet the challenging and complex IV therapy requirements of the modern-day patient. For vascular access devices (VAD) to be a safe and effective tool for the administration of IV therapy, they must be reliable. Reliability in this context refers to optimal catheter function, demonstrated by the ease of flushing and aspirating, combined with an absence of associated complications. Proficient care and maintenance of these devices by healthcare professionals requires a high degree of knowledge, skill and understanding. In this section, we explore the details of flushing by examining how, why, when and with what solution vascular devices are to be flushed.
\end{abstract}

\section{Keywords}

Flushing $\cdot$ Flushing technique $\cdot$ Flushing and locking $\cdot$ Flushing solutions $\cdot$ Flushing volume

\subsection{Introduction}

Flushing of a VAD is a crucial intervention that facilitates a proactive approach in relation to maintaining catheter patency and function. It also supports complication prevention, surveillance and early escalation to relevant multidisciplinary team (MDT) members when limitations are met. Absent, untimely or ineffective flushing can cause catheter malfunction and result in associated complications such as occlusion, thrombosis and infection, which can increase patient morbidity and mortality (Baskin et al. 2012). Consequences of inadequate flushing could include negative patient outcome and experience, treatment delays, costly thrombolytic therapy, antimicrobial therapy, device removal and reinsertion, increased hospital stay and organisational costs (Mitchell et al. 2009). Maintaining the function of VADS for patients is therefore an essential responsibility that should be carried out by skilled health professionals using the best available scientific evidence (Anderson et al. 2010; Moureau et al. 2013).

\subsection{Flushing Rationale}

Proper flushing techniques are effective, inexpensive and associated with good clinical practice (Ferroni et al. 2014). National and international guidelines include flushing recommendations in 
concurrence with manufacturer instructions for use (IFUs) to optimise VAD safety, function and durability, for all patients requiring short- to long-term IV therapy (RCN 2016; Gorski et al. 2016; Lyons 2012; Loveday et al. 2014).

The Royal College of Nursing (2016) advocates flushing to maintain catheter patency and prevent the mixing of incompatible medications that may precipitate and occlude the lumen (Baskin et al. 2012). This endorsement is echoed by the Infusion Standards of Practice (Gorski et al. 2016), which highlight the importance of flushing as a method of assessing catheter function, identifying malfunction and minimising the risk of occlusion, thrombus and catheter-related bloodstream infection (CRBSI).

Ideally, the lumen of a vascular device should flush freely without resistance (Hadaway 2009) and is classed as malfunctioning if flushing and/or aspiration becomes difficult or impossible (Goossens 2016). Sluggish infusion and aspiration are caused by the accumulation of blood, fibrin and/or drug deposits that adhere to the internal surface and the tip of the catheter, leading to total occlusion if not adequately rinsed away (Hadaway 2006b; Dougherty and Lister 2015).

Flushing in the context of rinsing a catheter, can be defined as a manual injection of $0.9 \%$ sodium chloride or normal saline (NS) for the purpose of cleaning the internal walls of the lumen (Goossens 2015). Compared to other forms of VAD management, the act of flushing, when performed correctly, represents a key procedure in maintaining patency by preventing occlusion (Royon et al. 2012) and minimising the potential for the adherence of harmful microorganisms that can lead to biofilm formation and catheter related blood stream infection [CRBSI] (Hadaway 2006b, 2009; Goossens 2013).

Flushing a vascular access device using the proper technique, at the right time, and with the correct solution and volume should not be underestimated (Goossens 2015). Flushing of catheters initially appears to be a straightforward concept. However, flushing is much more than just injecting fluid into a catheter lumen (Hadaway 2009); it requires knowledge of flushing techniques and needle-free connectors by the healthcare professional providing the hands-on care (Moureau 2013).

\subsection{Flushing and Locking Principles}

The basic principles that underpin an effective VAD flushing and locking technique, include adequate rinsing or flushing of the catheter, (Goossens 2015) followed by instillation of a solution lock, that will reside witin the inner lumen. This prevents blood reflux into the tip of the catheter, blood coagulating within the VAD lumen and maintains patency inbetween infusions (Gorski 2016). Locking an approved solution into a VAD, creates a column of fluid inside to help maintain lumen patency (Hadaway 2012). According to NICE (2017) guidelines, a sterile $0.9 \%$ sodium chloride injection should be used to flush and lock catheter lumens (NICE CS174, 2017). Antibiotic lock solutions should not be routinely used to prevent CRBSIs (NICE 2017), as low-level exposure of antibiotics may potentially increase the risk of resistance (Justo and Bookstaver 2014).

National guidelines recommend peripheral cannulas are flushed and locked with $0.9 \%$ sodium chloride only (Gorski et al. 2016). There is insufficient evidence to suggest heparin-saline solution is more effective than $0.9 \%$ sodium chloride, in maintaining lumen patency (Randolph et al. 1998), and heparin is known to cause serious adverse effects in susceptible patients (Alexander 2010). This topic will be discussed in greater depth later in the chapter. Studies have successfully demonstrated that flushing and locking technique is considered more important than the solution used, to adaquately clean and prevent blood reflux into the catheter, when maintaining VADs and to prevent VAD associated infection (Ferroni et al. 2014, Guiffant et al. 2012).

Central venous access devices (CVADs) can be locked with various solutions ranging from $0.9 \%$ sodium chloride, anticoagulation therapy (Heparin/ hepsal) and thrombolytic therapy (urokinase/ alteplase) to antibiotic treatment (Hadaway 2006a). The lock objective is to maintain lumen patency, restrict blood reflux and, depending on the solution instilled, prevent thrombus or fibrin formation in or around the catheter tip. Locking can also be used to break down an existing clot or treat an infection by penetrating and breaking apart any existing intraluminal biofilm (Goossens 2015). 


\subsection{Optimal Flushing}

A combination of two flushing methods is recommended to facilitate effective VAD rinsing and locking objectives: use of a pulsatile flushing technique and the application of positive pressure at the end of the flush (RCN 2016). These methods are directly associated with specific flow dynamics, which impact the quality of the flush in terms of achieving the desired effect (Goossens 2015). Most non-infective VAD-associated complications can be minimised and even prevented by strict adherence to standardised flushing protocols (Pittiruti et al. 2009).

A pulsatile flush involves a rapid stop-start or push-pause technique as the solution is injected into the catheter. Studies have shown that the resulting turbulent flow created by the pushpause technique is considerably more effective at rinsing the lumen, in comparison to a continuous laminar flow (Vigier et al. 2005; Guiffant et al. 2012). This technique has also been found to significantly reduce catheter, bacterial attachment and growth in VADs, in comparison to a continuous flushing method without the turbulence (Ferroni et al. 2014). In addition, a time interval of $0.4 \mathrm{~s}$ between two boluses is a critical factor, to optimise effective flushing (Guiffant et al. 2012). These studies are suggestive that a manual pulsatile, positive pressure flush of $10 \mathrm{~mL}$ is administered immediately before and after any IV infusion.

Hydrodynamics coupled with an intermittent flushing method is an important contributing factor that effectively removes proteins and other adhering substances from the endoluminal wall of a vascular device (Ferroni et al. 2014). Pulsatile flushing must therefore be considered a key strategy in occlusion and infection prevention, as clearing the catheter lumen of all traces of blood and medications can reduce the potential for bacterial adhesion and colonisation, leading to CRBSI (Ferroni et al. 2014; Moureau 2013). VAD-associated infection is increasingly being regarded as a measure for quality of care within healthcare settings (Bodenham et al. 2016). There is currently zero tolerance for VAD-associated infections within health care organisations, as they are considered a preventable complication if the correct infection prevention techniques are adhered to.

\subsection{Flushing Technology}

In addition to good technique, effective flushing is enhanced by specifically designed technology and an understanding of how effective technology and flushing work together (Hadaway 2006b). Understanding is critical because optimum flush outcome relies heavily upon the knowledge and skills of the healthcare worker to perform the correct technique, whilst considering the assisting technology design and function (Goossens 2015). Evidence demonstrates that adequately trained and educated health professionals who adhere to practice guidelines when accessing and flushing VADS achieve the best patient outcomes (Moureau 2013). This knowledge must extend to the variety of medical devices available that aid flushing and optimisation of VAD management, such as integrated catheter valves, pre-filled syringes and neutral or positive displacement needle-free connectors (Goossens 2015). These innovations along with evidence-based clinical practices have led to advances in vascular access, improved safety and reduced complication rates (Krzywda and Andris 2005).

\subsection{Pre-filled Syringes}

One of the technological answers to help eliminate the 'rebound' problem and inadvertent blood reflux is to use a commercially prepared syringe, pre-filled with $0.9 \%$ sodium chloride (Fig. 19.1) (Hadaway 2009). Pre-filled syringes have a plunger rod design to maintain application of positive pressure whilst flushing (Goossens 2015). Pre-filled syringe flush volumes are available in 3, 5 and $10 \mathrm{~mL}$ options for various VAD type, length and size. The smaller volume prefilled syringes are produced in diameters and dimensions consistent with a $10 \mathrm{~mL}$ syringe barrel (Keogh et al. 2016), generating significantly less pressure (Gorski et al. 2016) than standard 5 and $3 \mathrm{~mL}$ syringes. Flushing vascular access 


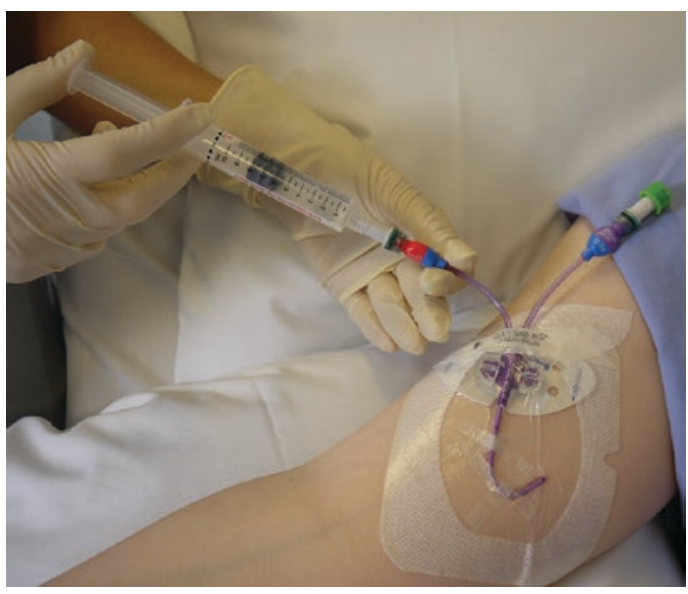

Fig. 19.1 Saline flushing with $10 \mathrm{~mL}$ pre-filled syringe (Used with permission of the Royal Liverpool University Hospital)

devices incorrectly, by exerting high pressures with smaller syringes than the manufacturer's recommendations, suggests that it may contribute to catheter rupture, especially if resistance is met on flushing the device (Bishop et al. 2007; Pittiruti et al. 2009; Goossens 2015; Hadaway 2006b; Miyagaki 2012). Pre-filled syringes are recommended for use in relevant guidelines (Gorski et al. 2016; RCN 2016) as they aid optimal flush objectives, by promoting zero blood reflux, reduce the amount of pressure exerted against the inner catheter wall and minimise vein injury (Keogh et al. 2016).

Silicone VADS such as non-powered peripherally inserted catheters (PICCS) and tunnelled central venous catheters are more prone to fracture than polyurethane devices that have superior strength and are power-injectable (Ong and Sudhakar 2010; Goossens 2015). Consequently, an increasing number of VADS, particularly peripherally inserted central catheters (PICCS) and totally implantable venous access devices (TIVADS), are using improved polyurethane, able to withstand higher pressures. This calls into question the strict use of $10 \mathrm{~mL}$ diameter standard syringes for flushing, which may eventually become redundant if VAD materials can withstand the high pressure of power injection (Goossens 2015). Currently, however, the RCN (2016) infusion guidelines and manufacturer's instructions for use continue to recommend a $10 \mathrm{~mL}$ syringe option to flush vascular access devices, including for use with powered devices.

A manual, positive pressure technique required for use with a standard syringe may not be necessary when flushing with pre-filled syringes designed to reduce syringe plunger reflux. The innovative design prohibits the rod plunger from rebounding at the end of the flush, allowing for total emptying of the solution from the barrel prior to disconnection (Data on file Excelsior Medical, LLC http://swabflush.excelsiormedical.com/zr-flush-syringes/). However, removal of the syringe tip from the needle free connector prior to clamping, will cause reflux related to tip volume displacement (Hadaway 2006b).

\subsection{Positive Pressure Flushing}

A correct, positive pressure technique when using a standard $10 \mathrm{~mL}$ syringe, requires a constant, even force on the syringe plunger during flushing, to create an effective means of preventing backflow of blood or reflux into the catheter tip (Gorski et al. 2016; Goossens 2015). This form of flushing is recommended in combination with a pulsatile technique for maximum efficiency (RCN 2016), which depends more on technical practice than the flushing solution used (Royon et al. 2012; Pittiruti et al. 2009). Ineffective positive pressure results in a rebound effect that pulls blood into the catheter tip as the syringe is detached from the hub, also known as reflux (Hadaway 2009). This problem can be overcome by maintaining the forward positive flow of solution as the syringe is removed towards the end of the flush $(0.5-1 \mathrm{~mL}$ remaining) whilst simultaneously applying pressure to the plunger (Bishop et al. 2007; Goossens 2015). This technique often results in an external spray of fluid (Hadaway 2009) indicating positive pressure has been applied correctly. This method can also be applied successfully by clamping the catheter just prior to injecting the last $1 \mathrm{~mL}$ of flushing solution, if external clamps are present (Goossens 2015). It is necessary to fasten external clamps 
when the catheter is not in use to prevent backflow of blood into the lumen.

When recommended by the manufacturer, implanted ports or non-valved, open ended catheter lumens should be flushed and locked with heparin sodium flush solutions. Positioning the Huber needle bevel towards the port body catheter connection increases flush efficacy within the port (Guiffant et al. 2012). Application of positive pressure (achieved by the injection of additional solution) during Huber needle withdrawal reduced the incidence of reflux by nearly $80 \%$ (Lapalu 2010). This study demonstrates the value of positive pressure to port patency and complication reduction and supports the use of applying positive pressure during port needle removal.

An experimental study designed to quantify the impact of positive pressure application during an implantable port needle removal has demonstrated statistically significant results, depending on whether or not positive pressure was used during the removal process (Lapalu 2010). The studies findings report the creation of negative pressure on the port septum during Huber needle removal when positive pressure was not applied. This negative pressure was found to cause a suction effect resulting in an upward movement of the septum at the distal catheter tip, followed by an unwanted influx of blood.

\subsection{Blood Reflux}

Despite optimal flushing and locking techniques, there are external influences that displace the internal locking volume causing blood to reflux into the catheter. Body or muscle movements, intrathoracic pressure changes caused by coughing or vomiting, arm abduction or adduction, application of blood pressure cuff, catheter mechanical changes of clamping and unclamping, syringe plunger rebound in certain syringes after flushing and connection and disconnection of syringes or needle free connectors, all cause pressure changes within a catheter that may pull blood into the catheter tip (Goossens 2015; Hadaway and Richardson 2010). Neutral or antireflux needle free connector technology should theoretically prevent blood reflux from occurring; however, it is suggested by Hadaway and Richardson (2010) that up to $0.02 \mathrm{~mL}$ of blood can still be drawn into the catheter tip depending on theneedle free connector design and clamping sequence followed by clinicians (Hadaway and Richardson 2010). Unwanted reflux volumes have also been demonstrated by other researchers (Elli et al. 2016; Hull et al. 2018). It is therefore rational to conclude that proper flushing techniques can only guarantee the prevention of blood reflux into the catheter tip at the very instant the catheter is being locked (Goossens 2015).

Different types of needle free connectors (positive, negative, neutral and anti-reflux), each with a recommended clamping sequence, create confusion among clinical users. Blood reflux occurs when needle free connectors are used with improper clamping sequences. This suggests a timely, manual flush with the correct technique or pre-filled syringe is advisable immediately post disconnection with an appropriate clamping sequence to follow. Without clamping or an antireflux valve, the flushing may provide a shortterm solution to compensate for backflow of blood, which may later lead to patency problems and potentially other associated complications (Hadaway 2006b). Timely and efficient flushing of VADS using the correct technique for clamping and flushing the needle free connector is therefore critically important to ensure optimal removal of blood or other medications or infusions (Ferroni et al. 2014).

Investigative in vitro (Agharazii et al. 2005; Polaschegg and Shaht 2003; Sungur et al. 2007; Polaschegg 2005) and in vivo (Markota et al. 2009; Barbour et al. 2015) studies have demonstrated significant early- and late-stage leakage of locking solution into the systemic circulation during and after the administration process. The most significant losses occur during lock instillation (Agharazii et al. 2005; Markota et al. 2009; Polaschegg and Shaht 2003; Sungur et al. 2007; Barbour et al. 2015) which can account for up to 25-30\% of the total lock volume (Barbour et al. 2015). Depending on fluid dynamics and catheter compliance and speed of instillation during the 
locking process, the lock volume and concentration at the catheter tip can be greatly reduced and replaced by an unwanted reflux of blood (Polaschegg and Shaht 2003).

Instillation leakage is a result of inertia due to flow velocity, that develops inside the catheter lumen as it is filled, transporting the locked solution out into the systemic circulation (Barbour et al. 2015), and is associated with the rate (or propulsion) at which administration occurs (Barbour et al. 2015; Agharazii et al. 2005). An in vitro study comparing a lock injection time of 2-3 and $23 \mathrm{~s}$ found this to have negligible influences upon the dynamics of the loss (Polaschegg 2005). Contrary to these findings, a subsequent in vivo study recommends a slower rate of lock instillation, as it may result in less initial leakage and should therefore be considered (Barbour et al. 2015).

In vitro studies use static flow and environmental conditions to study lock leakage rates; however, these models do not consider the numerous parameters that can affect the catheter leakage in vivo (Markota et al. 2009). Contrastingly, in vivo studies use experimental models of the SVC that mimic its internal, rhythmical flows that follow each heartbeat (Agharazii et al. 2005). In vivo experiments are thought to produce more accurate data as they simulate realistic, physiological conditions; however, they do have their limitations (Barbour et al. 2015; Markota et al. 2009).

Regardless of the care taken to instill a locking solution, both types of studies have demonstrated a secondary, more gradual leakage of the locked volume that occurs because of convective and diffusive transport (Barbour et al. 2015; Markota et al. 2009). In vitro studies have demonstrated secondary losses as high as $70-80 \%$. However, this is not consistent with more reliable in vivo reports which show much smaller losses of $2 \%$ loss over a 24-h period, which are attributed to the low diffusivity of the lock solution (Barbour et al. 2015). Convective fluxes within the pulsatile, dynamic environment of the SVC surround the catheter and act to rapidly deplete the near-tip lock concentration. Diffusive fluxes draw more locking solution from the internal lumen back into the near-tip region, only to be transported immediately away by blood-driven convective currents (Barbour et al. 2015).

CVADs with distal side holes situated at the catheter tip (found on dialysis, apheresis and non-tunnelled catheters) are potentially more susceptible to convective fluxes than CVADs without side holes (Barbour et al. 2015). An in vivo study conducted by Markota et al. (2009) concludes that early and late leakages are significantly higher in non-tunnelled catheters compared to tunnelled catheters $(p=0.05)$ that do not have proximately situated holes (Markota et al. 2009). Catheters without side holes are likely to be less susceptible to convective fluxes and therefore more conducive to maintaining lock concentration (Barbour et al. 2015). Data collected from these studies have contributed to a greater understanding of lock depletion in and around the central venous catheter tip (Markota et al. 2009); however, more research is needed in this area.

\subsection{Needle-Free Connectors}

Since their introduction in the early 1990s, needle-free connectors (NFCs) have successfully achieved their original purpose of minimising the risk of needle stick injury posed to healthcare providers accessing vascular devices (Hadaway 2012; Moureau and Flynn 2015). This technology is now commonly used to facilitate needlefree connection between catheters, administration sets and syringes (Jarvis 2010), creating a closed system between the internal vasculature and the external environment, via a Luer connection to the catheter hub (Moureau and Flynn 2015).

Despite achieving the original objective, many published studies have raised concerns regarding an association between NFCs and increased risk of CRBSI and catheter occlusion (Hadaway 2012; Ryder 2010; Field 2007; Jarvis et al. 2009; Marschall et al. 2014). This association of increased risk of CRBSI with positive pressure NFCs (Ryder 2010) has prevented them from being actively recommended in certain guidelines (Pittiruti et al. 2009). Studies have demonstrated that during disconnection of a syringe or intravenous tubing from the NFC, pressure 
Table 19.1 Needle-free connector displacement functions (Hull et al. 2018)

\begin{tabular}{l|l|l|l|l}
\hline Types of NFCs & $\begin{array}{l}\text { Negative } \\
\text { displacement NFC }\end{array}$ & $\begin{array}{l}\text { Neutral } \\
\text { displacement NFC }\end{array}$ & Anti-reflux NFC & Positive displacement NFC \\
\hline $\begin{array}{l}\text { Fluid movement upon } \\
\text { disconnection }\end{array}$ & $\begin{array}{l}\text { Blood refluxes into } \\
\text { the catheter }\end{array}$ & $\begin{array}{l}\text { Blood refluxes } \\
\text { into the catheter }\end{array}$ & $\begin{array}{l}\text { Fluid restricted } \\
\text { by diaphragm }\end{array}$ & $\begin{array}{l}\text { Fluids moves towards } \\
\text { patient }\end{array}$ \\
\hline $\begin{array}{l}\text { Fluid movement upon } \\
\text { connection }\end{array}$ & $\begin{array}{l}\text { Fluid moves } \\
\text { towards patient }\end{array}$ & $\begin{array}{l}\text { Fluid moves } \\
\text { towards patient }\end{array}$ & $\begin{array}{l}\text { Fluid restricted } \\
\text { by diaphragm }\end{array}$ & $\begin{array}{l}\text { Blood refluxes into } \\
\text { catheter }\end{array}$ \\
\hline $\begin{array}{l}\text { Manufacturer } \\
\text { recommended } \\
\text { clamping sequence }\end{array}$ & $\begin{array}{l}\text { Clamp before } \\
\text { disconnection }\end{array}$ & $\begin{array}{l}\text { No specified } \\
\text { clamping }\end{array}$ & $\begin{array}{l}\text { No specified } \\
\text { clamping }\end{array}$ & Clamp after disconnection \\
\hline
\end{tabular}

changes within the catheter cause varying degrees of fluid movement or displacement resulting in unwanted blood reflux into the catheter tip (Hull 2018; Elli et al. 2016). Improving clinical outcomes for patients by reducing complications such as CRBSI and VAD occlusion has propelled modern NFC design to incorporate an internal mechanism that reduces fluid displacement within the intravascular device (Kelly et al. 2017; Hadaway 2012). Used correctly, NFCs are of great benefit to assist in the successful care and maintenance of VADs; however, they are only as safe and reliable as the individuals that use them (Hanchet 2005).

Confusingly there are four different types of NFC. Each has a complex mechanical valve design and are marketed as either negative, neutral, positive displacement or anti-reflux depending on the characteristics of the internal mechanism and action of fluid displacement upon connection and disconnection from a syringe or tubing (Btaiche et al. 2011; Elli et al. 2016; Hull et al. 2018). Hull et al. (2018) have published a clear and concise summary (Table 19.1), revealing the details associated with different fluid displacement mechanisms and recommended clamping sequence for each type of NFC.

Optimal management of NFCs depends upon an understanding of the type of NFC, the internal membrane and valve function and method of recommended flushing and clamping for each. INS (2016) acknowledge the sequence for flushing depends on the particular NFC used and warns of the potential for confusion and inconsistency within healthcare workers who are not aware of the differences (Gorski et al. 2016; Hadaway 2012; Kelly et al. 2017). Lack of knowledge, skill and understanding can result in VAD misman- agement, leading to an increased risk of reflux and VAD-associated complications (Kelly et al. 2017). Applying the same management to all NFCs can result in an increased occlusion rate due to blood reflux after flushing (Elli et al. 2016). There is still much debate within the literature regarding the most effective NFC design and therefore a need for further research into the area of reflux, valves, NFC and the impact they have on device function (Kelly et al. 2017; Jarvis 2010). It is therefore recommended that healthcare organisations standardise the choice of NFC to one brand/style of needless connector, to help employees understand design characteristics and maximise proficiency in use (Jarvis 2010; Hadaway 2012). Used correctly, NFCs are of great benefit, functioning as a closed system to assist in the care and maintenance of VADS and are one of the main contributors to catheter patency (Elli et al. 2016). Proper care, maintenance and management of NFCs enhance patient safety and the durability of vascular access devices (Kelly et al. 2017).

\subsubsection{Negative Displacement Connectors}

A negative displacement connector is designed to allow a two-way flow of fluid for infusion and aspiration and will permit blood reflux into the catheter during connection and disconnection, including when the administration set, or syringe is attached and detached (Hadaway and Richardson 2010). This is caused by movement of the inner valve mechanism (Hadaway 2012) and is a potential contributing factor of thrombotic occlusion (Btaiche et al. 2011) and biofilm 
formation (Jarvis 2010) if a proper flushing technique or clamping sequence is absent or ineffective post disconnection from the hub (Hadaway and Richardson 2010).

\subsubsection{Positive Displacement Connectors}

Positive needle-free connectors are designed to compensate for an ineffective or absent flush (Hadaway 2006b). User knowledge and understanding is vital if complications are to be avoided with this type of NFC design (Hadaway and Richardson 2010). The internal mechanical valve has a fluid reservoir for withholding a small amount of solution, which is passively expelled upon disconnection, preventing a residual flow of blood into the lumen (Btaiche et al. 2011). The resulting positive displacement can only occur after disconnection has taken place (Btaiche et al. 2011). If disconnection fails to happen, negative pressure is created within the system followed by an influx of blood into the catheter lumen (Hadaway and Richardson 2010). This is a major contributing factor of preventable VAD occlusion and can happen regardless of NFC used. A time delay following disconnection is recommended by manufacturers to facilitate the positive fluid displacement effect (Hadaway 2006b).

\subsubsection{Neutral Displacement Connector}

A neutral displacement mechanism is designed to work by inhibiting movement of solution in either direction when connecting to and disconnecting from the device, preventing fluid displacement into the catheter lumen (Btaiche et al. 2011). A study comparing neutral with positive needle-free connectors demonstrated improved occlusion rates $(26 \%)$ with the neutral connector option, but failed to show any difference in rates of infection. Findings were not statistically significant, but staff satisfaction was higher with the neutral device resulting in its implementation throughout the healthcare organisation (Logan 2013).

\subsubsection{Anti-reflux Connectors}

Anti-reflux NFC entered the market following concerns over increased infection and occlusion caused by NFC use (Jarvis et al. 2009; Macklin 2014). The design of the anti-reflux NFC is based on a pressure-sensitive valve that allows opening for infusion when pressure increases, closes when pressure drops or not in use and inverts when negative pressure is applied (Hull 2017; Elli et al. 2016). Jasinsky and Wuester (2009) demonstrated statistical significance with the reduction of occlusion of CVADs from $30 \%$ to $7.6 \%$ with use of an anti-reflux NFC; later the study was expanded to include peripheral intravenous catheters, resulting in lower phlebitis rates and longer dwell times (Jasinsky and Wuerster 2009).

Recent studies have found anti-reflux connectors are having a positive impact in maintaining patency and reducing occlusion rates and catheter malfunction (Jazinsky and Wuerster 2009, Elli et al. 2016, Hull 2018, County Durham and Darlington NHS Foundation trust). A quantitative, in vitro study conducted by Hull et al. (2018) demonstrates minimal fluid movement upon connection and disconnection of anti-reflux NFCs and suggests these devices should be considered for incorporation into clinical practice (Hull 2018). The study adds that more research is needed in this area.

\subsection{Integrated Catheter Valves}

Catheters which have an integrated valve were originally designed to maintain lumen patency and reduce catheter occlusion rates, by preventing retrograde blood flow (Hoffer et al. 1999, 2001). Multiple designs of these valves exist and are located at the distal or proximal end of the catheter (Gorski et al. 2016). Integral valves function as an automatic clamp (Hoffer et al. 1999), locking the instilled solution and theoretically minimising blood reflux into the catheter tip (Carlo et al. 2004). The recommended locking solution for valved devices is $0.9 \%$ sodium chloride (Gorski et al. 2016). 


\subsubsection{Other Factors Affecting Blood Reflux}

Neutral or anti-reflux NFCs, non-rebounding syringes and other assisting technologies like integrated catheter valves are currently recommended, alongside timely effective flushing techniques and health professional knowledge, in national and international guidelines, to assist in VAD maintenance, facilitating optimal removal of blood or other intraluminal debris from medications and infusions (Ferroni et al. 2014). To maximise catheter lumen patency, neither technique nor technology can stand alone (Hadaway 2006b). Guidelines also always suggest adherence to local policy and manufacturer's instructions for use (RCN 2016; Lyons 2012; EPIC 3 2014; ESPEN 2009; Gorski et al. 2016). Short peripheral catheters, extended dwell catheters, midlines and PICCs may be particularly affected by blood reflux due to small lumen size and greater surface area.

\subsection{Flushing and Locking Volumes}

\subsubsection{Flushing Volumes}

The intraluminal volume capacity and required flushing volumes for venous catheters can vary considerably depending on the patient group, type of catheter, nature and type of infusion or medication used (RCN 2016). Flushing should continue until all blood, fluid and medication residue is cleared (Moureau 2013), and a larger volume may be required post blood sampling or post blood transfusion procedures (Gorski et al. 2016). Blood or medication residue can lead to partial or complete occlusion, which is linked to blood stream infection, as microorganisms introduced into the catheter over time develop into a biofilm-fibrin combination (Hadaway 2009). Adherence to evidence-based infection control practices (evidence-based hand washing standards and proficient ANTT) combined with effective flushing and locking techniques can sustain VAD patency and reduce complication risk such as CRBSI (Moureau 2013; Gorski et al. 2016).

Current guidelines suggest the quantity of solution needed to adequately flush a lumen should be equal to twice the internal volume of the catheter system, which includes the catheter extension set and/or needle-free injection system added to the catheter hub (Gorski et al. 2016; RCN 2016). This translates into $3-5 \mathrm{~mL}$ for a peripheral intravenous cannula (Keogh et al. 2016) and $10 \mathrm{~mL}$ for a central venous catheter (Bishop et al. 2007), increasing to $20 \mathrm{~mL}$ post blood sampling or when rinsing vesicant medications from CVADs (Goossens 2015; Guiffant et al. 2012). These volumes far exceed twice the internal volume (Goossens 2015) recommended in the INS (2016) and RCN guidelines (2016); however, this excess should guarantee sufficient rinsing of the lumen, especially for longer central venous catheters, and TIVADS in particular, that can accumulate debris or sludge in the port reservoir if inadequately flushed (Goossens 2015).

\subsubsection{Locking Volumes}

Locking refers to the installation of fluid into a catheter lumen after the completion of the last flush (Gorski et al. 2016) to maintain patency between infusions and/or reduce the risk of CRBSI (Gorski 2016). Types of locking solutions include saline, heparin, antibiotics, thrombolytics, citrate, ethanol and bicarbonate solutions. Catheter manufacturers specify precise intraluminal volume to assist the healthcare provider to instill the amount of lock solution required and reduce the risk of overspill into the patient's circulation (Polaschegg and Shaht 2003). Physiologic solutions, such as saline, are used as both flushing and locking solutions with the volume dictated by the judgement of the clinician. It is recommended that organisational locking policies and practice guidelines be in accordance with manufacturer's instructions for use and guidelines (Gorski et al. 2016).

Caution must be taken with lock solutions that can potentially cause adverse effects if excess amounts spill into the systemic circulation 
(Polaschegg and Shaht 2003). Some thrombolytic agents used to restore catheter patency by resolving thrombotic occlusion (CummingsWinfield and Mushani 2008) may be particularly dangerous (Bunce 2003). The most serious adverse reactions to this type of drug in clinical trials include sepsis, gastrointestinal bleeding and thromboembolism (Bunce 2003). Other thrombolytic agents indicated for clearance of catheter occlusions have demonstrated safety and efficacy when used according to the labelling instructions (Baskin et al. 2009; Deitcher et al. 2002; Ponec et al. 2001; Semba et al. 2002).

The Lyons guidelines (2012) advocate the use of the thrombolytic drug, human urokinase $(10,000 \mathrm{U} / \mathrm{mL})$, reconstituted with $4 \mathrm{~mL} 0.9 \%$ saline, using $2 \mathrm{~mL}$ of this solution to lock each lumen (Bishop et al. 2007). This recommendation is to ensure that the intraluminal volume or internal space only is filled (Bishop et al. 2007). Insufficient locking volumes or underfilling can have negative clinical implications, especially if the prescribed treatment or prophylactic dose is depleted further during the instillation process and again due to convective losses post administration (Barbour et al. 2015).

As mentioned previously in this chapter, in vitro and in vivo studies have demonstrated significant lock leakage from the distal catheter tip of central venous catheters during administration and then gradually over time (Agharazii et al. 2005; Markota et al. 2009; Polaschegg and Shaht 2003; Polaschegg 2005; Sungur et al. 2007; Barbour et al. 2015). Locking volumes need to be enough to fill the entire catheter plus any add-ons (Goossens 2015) and surround the external near-tip region for maximum effectiveness (Barbour et al. 2015).

To compensate for any leakage from the instilled lock over time, it is suggested that catheters should be overfilled by approximately 15-20\%, plus up to $1 \mathrm{~mL}$ for any add-ons (Goossens 2015). However, this excess can only be recommended for physiologic locking solutions and not solutions with medications or substances that may cause adverse effects (Polaschegg and Shaht 2003; Polaschegg 2005; Goossens 2015).
Table 19.1 below provides guidance for lock solutions that do not cause adverse effects when injected into the bloodstream.

\subsection{Frequency of Flushing}

The expert consensus to date is that flushing should be carried out immediately before, inbetween and immediately after the administration of IV medications (RCN 2016; Gorski et al. 2016). This allows the practitioner to confirm catheter patency and function prior to use, prevent the mixing of potentially incompatible infusions and clear the lumen of any residue that may lead to associated complication (Gorski et al. 2016). CVADS that are not in frequent use should be flushed and locked weekly, with the exception of implantable ports that require monthly maintenance (Bishop et al. 2007).

Similar to flush volumes, there are limited studies that evaluate the effect of flush frequency on patient outcomes (Keogh et al. 2016). A randomised control trial (RCT) published by Keogh et al. (2016) is one of the first RCTs to evaluate the impact of different flushing volumes and frequencies on peripheral intravenous catheter (PIVC) outcomes in adult patients. This research was conducted in response to a growing concern of high cannula failure rates and variations in flushing practice. Patients were randomised to one of four flushing groups, to receive a manually prepared $0.9 \%$ sodium chloride flush of 10 or $3 \mathrm{~mL}$ every 24 or $6 \mathrm{~h}$. Results found that neither flushing volumes nor frequencies or their interaction together was significantly associated with cannula failure. Interestingly, however, cannula malfunction was demonstrated as being significantly associated with increased episodes of access. As a small pilot study, the author calls for larger, more definitive trials to provide more substantial data on the effect of flushing volume and flushing frequency on PIVC outcome (Keogh et al. 2016).

The following acronyms have been developed to assist healthcare professionals follow the correct flushing and locking regimes: 
SAS flushing recommendation (post IV medication/IV fluids)

\begin{tabular}{l|l}
\hline Saline (pre-flush) & $0.9 \%$ sodium chloride \\
\hline Administration of IV therapy & Medication or fluids \\
\hline Saline (post-flush) & $0.9 \%$ sodium chloride \\
\hline
\end{tabular}

SBS flushing recommendation (post blood sampling or blood product transfusions)

\begin{tabular}{l|l}
\hline Saline (pre-flush) & $0.9 \%$ sodium chloride \\
\hline $\begin{array}{l}\text { Blood sampling/blood } \\
\text { product transfusion }\end{array}$ & $\begin{array}{l}\text { Blood withdrawal or } \\
\text { administration }^{\text {a }}\end{array}$ \\
\hline Saline (post-flush) & $0.9 \%$ sodium chloride \\
\hline
\end{tabular}

${ }^{\mathrm{a}} \mathrm{A} 10-20 \mathrm{~mL}$ flush post blood transfusion is necessary because fibrin will develop with prolonged contact or blood reflux into the catheter and adhere onto the internal catheter wall (Goossens 2015)

SASH/SBSH flushing recommendation for implantable ports and open-ended central venous catheters (if recommended in the manufacturers instructions for use)

\begin{tabular}{l|l}
\hline Saline (pre-flush) & $0.9 \%$ sodium chloride \\
\hline $\begin{array}{l}\text { Administration of } \\
\text { IV therapy }\end{array}$ & Medication or fluids \\
\hline Saline (post-flush) & $\begin{array}{l}0.9 \% \text { sodium chloride } \\
\text { This varies depending on patient } \\
\text { population, local policy and } \\
\text { protocol and manufacturers } \\
\text { information for use }\end{array}$ \\
\hline OR & 0.9\% sodium chloride \\
\hline Saline (pre-flush) & $\begin{array}{l}\text { Blood withdrawal or } \\
\text { administration }\end{array}$ \\
\hline Blood transfusion/ sampling \\
blood sam
\end{tabular}

Flushing and locking recommendations 'based on research and insights' have been summarised in a review article by Goossens (2015) (Tables 19.2 and 19.3):

\subsection{Blood Return}

Flushing techniques cannot be thoroughly discussed without mentioning the importance of a blood return check prior to the administration of IV therapy via a CVAD. The absence of a blood
Table 19.2 Flushing and locking recommendations (Goossens 2015)

\begin{tabular}{l|l}
\hline Technique & $\begin{array}{l}\text { Use a pulsatile flow when flushing } \\
\text { Use a } 10 \mathrm{~mL} \text { flush with } 10 \times 1 \mathrm{~mL} \\
\text { boluses with a time interval of } 0.4 \mathrm{~s} \\
\text { between } 2 \text { boluses } \\
\text { Use SAS and SBS order for the } \\
\text { administration of medication/fluids and } \\
\text { blood sampling }\end{array}$ \\
\hline Volume & $\begin{array}{l}\text { Use a } 10 \mathrm{~mL} \text { flush for all IV catheters } \\
\text { (except peripheral cannulas, use 5 mL) } \\
\text { Use a } 20 \text { mL flush after infusion of } \\
\text { viscous products like blood components, } \\
\text { parenteral nutrition and contrast media }\end{array}$ \\
\hline Regimen & $\begin{array}{l}\text { Flush with NS before and after } \\
\text { administration of drugs and fluids (SAS) } \\
\text { Flush with NS before and after blood } \\
\text { sampling (SBS) }\end{array}$ \\
\hline
\end{tabular}

Table 19.3 Locking recommendations (Goossens 2015)

Technique Use the positive pressure technique when disconnecting a syringe

Close clamps and keep them closed when not in use

\begin{tabular}{l|l}
\hline Volume & 1.0 for peripheral cannulas \\
& 1.5 for midlines, PICCS, non-tunnelled \\
& CVADs and small-bore tunnelled \\
& catheters $(<1 \mathrm{~mm}$ ID) \\
& $\begin{array}{l}2.5 \mathrm{~mL} \text { for large bore tunnelled catheters } \\
(>1 \mathrm{~mm} \text { ID) and ports (reservoir volume }\end{array}$ \\
& $\begin{array}{l}\text { up to } 0.6 \mathrm{~mL}, \text { Huber needle volume not } \\
\text { included })\end{array}$ \\
\hline Regimen & $\begin{array}{l}\text { q8h-q24h for short-term catheters } \\
\text { Weekly in long-term catheters } \\
\\
\end{array}$ \\
\hline
\end{tabular}

return should result in an investigation and evaluation of potential causes (Gorski et al. 2016).

Blood return check does not apply to peripheral catheters as their correct position within the vein is assessed according to ease of flush and absence of signs that indicate tissue infiltration, inflammation or blockage (Loveday et al. 2014). Blood return check is relevant when a peripheral cannula is newly inserted; if patency cannot be established, it may be necessary to remove the device (Gorski et al. 2016).

Obtaining a brisk blood return on aspiration prior to administering IV therapy via a central venous catheter is a vital safety measure, recommended in relevant guidelines, to verify optimum function and catheter tip position within the SVC 


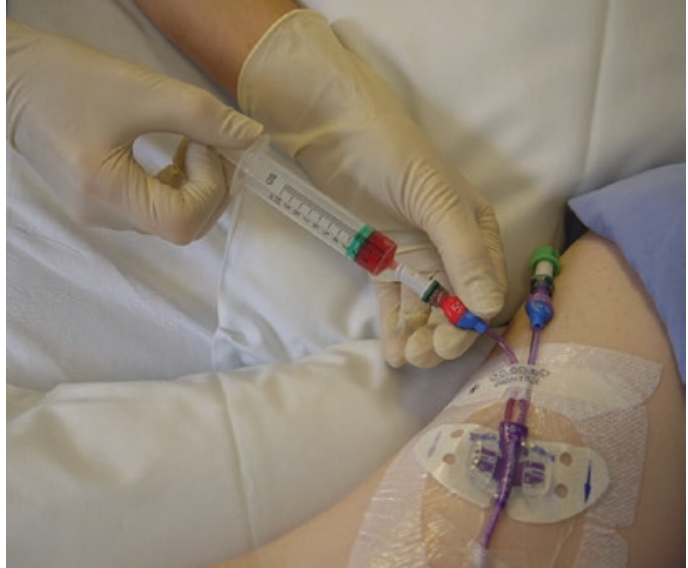

Fig. 19.2 Blood return aspiration and verification from PICC (Used with permission of the Royal Liverpool University Hospital)

(Fig. 19.2) (Gorski et al. 2016; RCN 2016; ESPEN 2009; Lyons 2012). The absence of blood return should prompt an attempt to flush the device (RCN 2016), and if this fails, action must be taken to investigate the potential root cause (RCN 2016; Gorski et al. 2016).

Absence of blood return on aspiration is more commonly due to thrombotic causes (Gorski 2016) such as fibrin sheath or tail formation (Pittiruti et al. 2009; Gabriel 2013). Fibrin is derived from fibroblastic tissue that gradually covers the intra- and extra-luminal surfaces of venous catheters and is associated with persistent withdrawal occlusion (ease of flushing but unable to withdraw blood) and occlusion (Pittiruti et al. 2009). Other potential causes can be attributed to the catheter tip abutting against the wall of the SVC, more common in left-sided placements (Rolden and Paniagua 2015), migration (Gabirel 2013; Bishop et al. 2007) and catheter tip malposition (Rolden and Paniagua 2015).

Undiagnosed CVAD malposition poses a serious but preventable risk to patient safety (Rolden and Paniagua 2015; Goossens 2016). Associated complications range from life-threatening, such as cardiac tamponade and intrathoracic infiltra- tion (Gorski et al. 2016), to a debilitating thrombus or progressive tissue damage (Sauerland 2005). In addition to conventional radiography to confirm or rule out malpositioning, assessment and investigation into catheter dysfunction is a strongly recommended safety measure within the current literature to maximise patient outcome (Gorski et al. 2016; Goossens 2013, 2016; Rolden and Paniagua 2015; Pikwer et al. 2008; Bishop et al. 2007; Hackert et al. 2005). Ongoing re-evaluation of CVAD function (ease of flushing and aspirating) can assist early identification of malposition and may prevent serious, CVADrelated complications (Goossens 2016). For example, absent blood return on aspiration is frequently documented in published case studies as a warning sign (Rolden and Paniagua 2015) and an important clue into the identification of catheter tip malposition, or a misplaced/dislodged Huber needle. These situations can result in serious safety implications for patients (Goossens 2013; Hackert et al. 2005; Pereira et al. 2013; Breitling 2010).

Pereira et al. (2013) presents two cases of malpositioned CVADs whereby the only clinical feature that indicated a problem was the absence of free flowing blood return. The case studies conclude that this safety check should not be undervalued (Pereira et al. 2013). Blood return check is not $100 \%$ infallible, as demonstrated by two case studies that report CVAD malposition despite successful aspiration of blood return (Losert et al. 2000; KlockgetherRadke and Gaus 2004). Interestingly, the authors continue to advocate periodic checking of CVAD function before every infusion of fluid or drugs due to the rare and unusual nature of the case circumstances (Losert et al. 2000).

These case studies demonstrate that no one, preventive measure alone, should be relied upon to diagnose malposition. The Infusion Nursing Standards of Practice Guidelines (2016) and the RCN 2016) strongly recommend that health professionals assess catheter function prior to use and advise investigation into 
potential malposition for CVADs that fail a blood return check. The absence of blood return may provide an invaluable sign, that can alert the clinician in the diagnosis of CVAD malposition. This may prompt other investigative measures such as the use of radio-contrast, as reported in a case by Breitling (2010), where serious patient harm was avoided. The consensus amongst experts is that a malpositioned catheter should be repositioned or removed and replaced as a priority (Rolden and Paniagua 2015; Gorski et al. 2016).

\subsection{Flushing and Locking Solutions: Heparin Versus Saline}

The use of heparinised solution to maintain CVAD function has been an accepted practice for decades (Anderson et al. 2010) despite the lack of definitive, high-quality evidence to support its continued use (Lopez-Britz et al. 2014; Hadaway 2006a). More emphasis is being placed on risk associated with heparin use from contamination issues or other disorders, and newer guidelines are reflecting the change to saline only, with elimination of heparin as a flushing agent for general use (Gorji et al. 2015). Heparin can result in serious side effects (Lopez-Britz et al. 2014) such as heparin-induced thrombocytopenia (HIT), heparin-induced thrombosis and thrombocytopenia syndrome (HITTS), allergic reaction, drug incompatibility and possible iatrogenic haemorrhage (Jonker 2010). Despite heparininduced disorders being uncommon (Anderson et al. 2010), it has been estimated that they can develop in up to $30 \%$ of patients with the possibility of occurrence 40 days after the cessation of heparin (Gorji et al. 2015). Even small concentrations of heparin can induce HIT in susceptible patients (Musliamani 2007), often with serious and life-threatening consequences (Anderson et al. 2010).

Given potential safety concerns with the use of heparin, $0.9 \%$ sodium chloride may be the preferred flushing and locking solution for short-term CVAD maintenance (RCN 2016; Loveday et al. 2014; NICE 2012). There is a growing body of evidence to suggest that flushing with $0.9 \%$ saline is equally as effective in preserving catheter patency (Pittiruti et al. 2009; Mitchell et al. 2009; Anderson et al. 2010; Jonker 2010; Shallom 2012; Lopez-Britz et al. 2014; NICE 2015; Gorji et al. 2015; Hoffer et al. 1999). Current guidelines recommend that short peripheral catheters be locked with preservative-free $0.9 \%$ sodium chloride following each catheter use in adults and children (Gorski et al. 2016). The ESPEN guidelines (2009) advocate sterile sodium chloride to flush and lock CVAD catheter lumens that are in frequent use for administration of parenteral nutrition $(\mathrm{PN})$, warning that heparin may facilitate the precipitation of lipids within the catheter lumen (Pittiruti et al. 2009).

The current evidence reported in the literature is of poor to moderate quality (LopezBritz 2014); however, the most recent study by Gorji et al. (2015) is a high-quality doubleblind RCT with a moderate cohort of 84 patients who were randomly assigned to two groups, to receive either heparin saline $(3 \mathrm{~mL})$ or $0.9 \%$ saline $(10 \mathrm{~mL})$. Results are consistent with an earlier, similar trial by Shallom (2012) demonstrating that heparinised saline did not have a statistically significant effect on improved patency and survival of CVADs compared with $0.9 \%$ sodium chloride (Gorji et al. 2015). More RCTs are needed to ensure National and International guidelines can be developed based on the best available scientific evidence (Anderson et al. 2010) to help organisations ensure the best possible experience and outcomes for patients.

A recent Cochrane Report (2014) comparing heparin with $0.9 \%$ saline flushes to prevent CVAD occlusion in adults analysed six studies with a combined total of 1433 participants. This systematic review found no compelling evidence to suggest that heparinised solutions were more effective than saline in reducing CVAD occlusion 
or associated complications such as thrombosis or infection (Lopez-Britz et al. 2014). The implications for practice section of the review acknowledge that heparin flushing and locking are currently a recommended practice in many guidelines and clinical settings. Lack of conclusive evidence combined with higher cost and potential side effects resulted in heparin not being recommended for use (Lopez-Britz et al. 2014).

NICE guidelines (2017) have developed this Cochrane Quality and Productivity topic and support its view that there is insufficient evidence to support heparin-based flushes. Recommendations are made to flush and lock CVAD catheter lumens with sterile $0.9 \%$ sodium chloride (NICE 2017). However, NICE guidelines also advise that when recommended by the manufacturer, implanted ports or open-ended catheter lumens should be flushed and locked with heparin sodium flush solutions (NICE 2017).

Guidelines such as EPIC 3 (Loveday et al. 2014), ESPEN (Pittiruti et al. 2009) and HICPAC (O'Grady et al. 2011) also recommend using sterile normal saline for injection to flush and lock catheter lumens that are accessed frequently, stating that manufacturers may recommend heparin flushes for implanted ports or open-ended CVADs that are accessed infrequently. Adherence to manufacturer's instructions is echoed in the guidelines published by NICE (2017), and the Infusion Standards of Practice (Gorski et al. 2016). Flushing with a heparin solution is recommended potentially useful for CVADs that are infrequently accessed or for patients receiving home $\mathrm{PN}$ or for ports (Pittiruti et al. 2009).

\subsection{Education and Flushing}

Effective VAD management starts with knowledge (Bunce 2003), which is why health professionals must have access to education and training, on how to effectively care for and maintain the wide variety of vascular access devices used in health care today (Moureau
2013). Clear, evidence-based guidelines should be available, easily accessible and, adhered to. This will standardise and facilitate best practice (Keogh et al. 2016; Sona et al. 2012), leading to improved patient satisfaction and outcome (Moureau 2013).

Epic 3 (2014) guidelines emphasise the importance of staff training, education and competency prior to caring for patients with intravascular catheters, whilst recommending healthcare workers have additional knowledge of manufacturer's advice relating to individual catheters, antiseptic solutions, dwell time and connections to ensure safe device use (Loveday et al. 2014).

\subsection{Conclusion}

Flushing is a fundamental clinical intervention, that will assist the maintenance and preservation of an optimally functioning vascular access device (Keogh et al. 2015). Flushing practices however, can vary, (Sona et al. 2012) relating to technique, frequency, volume and solution, which may be caused by conflicting recommendations and lack of education (Mitchel et al. 2009). Factors which influence proficient, clinical practice include practitioner compliance, knowledge and access to education (Moureau 2013; Loveday et al. 2014). Despite the current lack of concencous within the research literature (Keogh et al. 2015; Guiffant et al. 2012), there are studies that have generated enough evidence to inform current practice guidelines to support healthcare workers as they strive for and achieve the best possible outcome for patients.

\section{Case Study}

An interesting case study reported by Goossens (2013) was of a patient who received an implantable port for the administration of chemotherapy following a diagnosis of breast cancer. The first cycle of treatment was infused via the port following 
a satisfactory routine Huber needle insertion into the port. The port had a confirmed free-flowing blood return. The clinician administered saline with a pulsatile, positive pressure, nonresistant flush that was associated with no discomfort by the patient. During the second cycle of chemotherapy (28 days later), the port access was noted as difficult. A subsequent CXR failed to report any obvious device or catheter tip positioning problems. Access required six attempts to fix the Huber needle into the port septum. Flushing was without resistance; however, blood return was 'limited'. Despite these concerns chemotherapy treatment was administered. Within $30 \mathrm{~min}$ a painless red swelling was noted around the port, immediately prompting discontinuation of the infusion and port needle removal. The next day port assessment was conducted by an IV specialist nurse. During port needle insertion by the specialist, there was a notable absence of the needle tip abutting against the solid chamber bottom. More than $50 \mathrm{~mL}$ of NS was easily flushed; however, only 'pink-tinged' saline could be aspirated. Another attempt to access the port with a longer Huber needle was unsuccessful. A subsequent CXR revealed the implantable port chamber had rotated internally $180^{\circ}$. Root cause analysis of the study concluded that clinical warning signs of the needle tip not hitting the chamber bottom, absence of free-flowing blood return, despite the incorrect verification of port chamber position (on the initial CXR), should have prompted a corrective intervention prior to drug delivery. Risk factors for needle misplacement were noted as access by inexperienced clinicians and the absence of a brisk blood return. Recommendations are made for clinicians to have adequate skills and knowledge to be able to correctly choose needle length and be aware of what to expect during port (Huber) needle insertion. This case study demonstrated how a malpositioned, implantable port resulted in an extravasation injury and emphasises the importance of the need for skill and knowledge by health professionals when accessing vascular access devices to maximise patient safety, experience and outcome (Goossens G.A, Kerchaever I, Despierre E, Marguerite, S (2013) Access of a fully rotated implantable port leads to extravasation. J Vasc Access 14 (3): 299-300).

\section{Summary of Key Points}

1. Flushing is an integral clinical intervention to the maintenance and preservation of an optimally functioning vascular access device.

2. Flushing practices vary greatly regarding technique, frequency, volume and solution.

3 . There are a variety of types of needleless connectors including:

(a) Positive displacement connectors

(b) Negative displacement connectors

(c) Neutral displacement connectors

(d) Anti-reflux connectors

4. Each style of needless connector requires a specific clamping technique to prevent blood reflux.

5. To eliminate confusion and ensure patient safety, facilities should use one type of connector to ensure proper flushing and clamping technique, training and adherence by all clinicians.

6. Proficient care and maintenance of VADS requires a good degree of knowledge, skill and understanding.

7. Effective flushing requires a pulsatile, positive pressure technique to adequately rinse and lock the catheter. In 
addition to flow type, time interval between boluses is an important factor (Goossens 2015).

8. There is insufficient evidence to suggest heparinised solutions are more effective than $0.9 \%$ sodium chloride when locking VADS. Flushing technique is considered more important than solution used.

9. Pre-filled syringes are recommended for use in relevant guidelines ( $\mathrm{RCN}$ 2016; INS 2016).

10. Needle-free connectors (NFCs) reduce needle stick injury risk but can contribute to catheter occlusion and central line blood stream infection if not used correctly.

11. NFCs when used according to manufacturer's instructions can be of great benefit in assisting successful VAD care and maintenance by promoting patency and reduced complications.

12. Recent studies have found anti-reflux NFCs have a positive impact of maintaining VAD patency by reducing blood reflux into the catheter.

13. Flushing volumes should be equal to twice the internal volume of the catheter system, which includes the catheter extension set, and/or needleless injection system added to the catheter hub (RCN 2016; Gorski et al. 2016). Locking volumes should be overfilled by approximately $15-20 \%$ plus $1 \mathrm{~mL}$ for extension; only for physiologic solutions without adverse effects, VADS should be flushed immediately pre and post administration of IV therapy/blood sampling with $10 \mathrm{~mL} 0.9 \%$ sodium chloride. Increase to $20 \mathrm{~mL}$ post blood transfusion.

14. Blood return check post flush via a central venous access device (CVAD) may identify CVAD tip malposition. Absent blood return should prompt investigation into the root cause.

\section{References}

Agharazii M, Plamondon I, Lebel M, Douville P, Desmeules S. Estimation of heparin leak into the systemic circulation after central venous catheter heparin lock. Nephrol Dial Transplant. 2005;20(6):1238-40.

Alexander H. Heparin versus normal saline as a flush solution. Int J Adv Sci Arts. 2010;1(1):63-75.

Anderson BJ, Mitchell MD, Williams K, Umscheid C. A comparison of heparin and saline flush to maintain patency in central venous catheters. Nurs Times. 2010;106(6):15-6.

Barbour MC, McGah PM, Ng CH, Clark AM, Gow KW, Aliseda A. Conective leakage makes heparin locking of central venous catheters ineffective within seconds: experimental measurements in a model superior vena cava. ASAIO J. 2015;61(6):701-9.

Baskin J, Pui C, Reiss U, Wilimas J, Metzger M, Ribeiro R, Howard S. Management of occlusion and thrombosis associated with long-term indwelling central venous catheters. Lancet. 2009;374(9684):159-69. https://doi.org/10.1016/ s0140-6736(09)60220-8.

Baskin JL, Reiss U, Williams JA, Metzger ML, Ribeiro RC, Pui C-H, Howard SC. Thrombolytic therapy for central venous catheter occlusion. Haematologica. 2012;97(5):641-50.

Bishop L, Dougherty L, Bodenham A, et al. Guidelines on the insertion and management of central venous access devices in adults. Int $\mathrm{J}$ Lab Hematol. 2007;29(4):261-78.

Bodenham A, Babu S, Bennet J, et al. Safer vascular access. AAGBI Anaesth. 2016;71(5):573-85.

Breitling M. Malposition of a central venous catheter in the internal thoracic vein. Can J Anesth. 2010;57(S206):0832-610X.

Btaiche IF, Kovacevich DS, Khalidi N, Papke LF. The effects of needleless connectors on catheter-related thrombotic occlusions. J Inf Nurs. 2011;34(2):89-95.

Bunce M. Troubleshooting central lines. Mod Med Netw. 2003;66:28.

Carlo JT, Lamon JP, McCarthy TM, et al. A prospective randomised trial demonstrating valved implantable ports have complications and lower overall cost than nonvalved implantable ports. Am J Surg. 2004;188(6):722-7.

County Durham \& Darlington NHS Foundation Trust. Reducing the occlusion rates of peripheral midlines, our 5-year experience using Bionector TKO needle free connectors. CDDFT IV Team; 2016.

Cummings-Winfield C, Mushani T. Restoring patency to central venous access devices. Oncology Commons. 2008;12(6):925-34.

Deitcher S, Fesen M, Kiproff P, Hill P, Li X, McCluskey E, Semba C. Safety and efficacy of alteplase for restoring function in occluded central venous catheters: results of the cardiovascular thrombolytic to open occluded lines trial. J Clin Oncol. 2002;20(1):317-24. 
Dougherty L, Lister S. The Royal Marsden manual of clinical nursing procedures. 9th ed. Oxford: John Wiley \& Sons; 2015.

Elli S, Abbruzzese C, Cannizzo L, Lucchini A. In vitro evaluation of fluid reflux after flushing different types of needleless connectors. J Vasc Access. 2016;17(5):429_ 34. https://doi.org/10.5301/jva.5000583.

Ferroni A, Gaudin F, Guiffant G, Flaud P, Durussel JJ, Descamps P, Berche P, Nassif X, Merckx J. Pulsative flushing as a strategy to prevent bacterial colonisation of vascular access devices. Med Devices (Auckl). 2014;7:379-83.

Field K, McFarlane C, Cheng AC, Hughes AJ. Incidence of catheter-related blood stream infection among patients with a needleless valve-based intravenous connector on an Austrailian Hematology-Oncology Unit. SHEA. 2007;28(5):610-3.

Gabriel J. Venous access devices part 2: Preventing and managing complications of CVADS. Nurs Times. 2013;109(40):20-3.

Goossens GA. Diagnostic accuracy of the Catheter Injection and Aspiration (CINAS) classification for assessing the function of totally implantable venous access devices. Support Care Cancer. 2016;24(2): 755-61.

Goossens GA. Flushing and locking of venous catheters: available evidence and evidence deficit. Nurs Res Pract. 2015;2015:985686.

Goossens GA, Jérôme M, Janssens C, Peetermans WE, Fieuws S, Moons P, Verschakelen J, Peerlinck K, Jacquemin M, Stas M. Comparing normal saline versus diluted heparin to lock non-valved totally implantable venous access devices in cancer patients: a randomised, non-inferiority, open trial. Ann Oncol. 2013;24(7):1892-9.

Gorji MAH, Rezaei F, Jafari H, Cherati JY. Comparison of the effects of heparin and $0.9 \%$ sodium chloride solutions in maintenance of patency of central venous catheters. Anaesth Pain Med. 2015; 5(2):e22595

Gorski LA. Infusion therapy standards of practice. Home Healthcare Now. 2016;35(1):10-8.

Gorski L, Hadaway L, Hagle M, McGoldrick M, Orr M, Doellman D. Infusion therapy standards of practice. J Infus Ther. 2016;39:1S.

Guiffant G, Durussel JJ, Merckx J, Flaud P, Vigier JP, Mousset P. Flushing of intravascular access devices (IVADS) - efficacy of pulsed and continuous infusions. J Vasc Access. 2012;13(1):75-8.

Hackert T, Tjaden C, Kraft A, Sido B, Dienemann H, Buchler MW. Intrapulmonal dislocation of a totally implantable venous access device. World J Surg Oncol. 2005;3(1):19.

Hadaway L. Heparin locking for central venous catheters. J Assoc Vasc Access. 2006a; 11:224-3.

Hadaway L. Technology of flushing vascular access devices. J Infus Nurs. 2006b;29(3):137-45.

Hadaway L. Flushing vascular access catheters: risks for infection transmission. Infect Control Res. 2009;4(2):1-7.
Hadaway L. Needleless connectors for IV catheters. How to avoid complications associated with various models and practices. Am J Nurs. 2012;112(11):32-44.

Hadaway L, Richardson D. Needleless connectors. A primer on terminiology. J of Inf Nurs. 2010;33(1):22-31.

Hanchet M. Needleless connectors and bacteremia: is there a relationship? Infect Control Today 2005:1-9.

Hoffer EK, Borsa J, Santulli P, et al. Prospective randomised comparison of valved versus nonvalved peripherally inserted central vein catheters. Am J Roentgenol. 1999;173:1393-8.

Hoffer EK, Bloch RD, Borsa JJ, Santulli P, Fontaine $\mathrm{AB}$, Francoeur N. Peripherally inserted central catheters with distal versus proximal valves: prospective randomized trial. J Vasc Interv Radiol. 2001;12(10):1173-7.

Hull GJ, Moureau NL, Sengupta S. Quantitative assessment of reflux in commercially available needle-free IV connectors. J Vasc Access. 2018;19(1):12-22.

Jarvis WR. Choosing the Best Design for Intravenous Needleless Connectors to Prevent Bloodstream Infections. Infection Control Today. 2010;14(8).

Jarvis WR, Cathryn M, Hall KK, Fogle PJ, Karchmer TB, Harrington G, Salgado C, Giannetta ET, Cameron C, Sherertz RJ. Health care-associated bloodstream infections associated with negative or positive-pressure or displacement mechanical valve needleless connectors. Clin Infect Dis. 2009;49:1821-7.

Jasinsky LM, Wurster J. Occlusion reduction and heparin elimination trial using an antireflux device on peripheral and central venous catheters. J Infus Nurs. 2009;32(1):33-9.

Jonker MA, Osterby KR, Vermeulen LC. Does low dose heparin maintain central venous access device patency?: a comparison of heparin versus saline during a period of heparin shortage. JPEN. 2010;34(4):444-9.

Justo JA, Bookstaver PB. Antibiotic lock therapy: review of technique and logistical challenges. Infect Drug Resist. 2014;7:343-63.

Kelly LJ, Jones T, Kirkham S. Needle-free devices: keeping the system closed. Br J Nurs. 2017; 26(2):S14-9.

Keogh S, Flynn J, Marsh N, Higgins N, Davies K, Rickard CM. Nursing and midwifery practice for the maintenance of vascular access device patency. A cross-sectional survey. Int J Nurs Stud. 2015;52:1678-85.

Keogh S, Flynn J, Marsh N, Mihala G, Davies K, Rickard CM. Varied flushing frequency and volume to prevent peripheral intravenous catheter failure: a pilot, factorial randomised controlled trial in adult medical-surgical hospital patients. Biomed Central. 2016; $17: 348$

Klockgether-Radke AP, Gaus P. Malposition of a central venous catheter in a patient with severe chest trauma. Anasthesiol Intensivmed Notfallmed Schmerzther. 2004;39(5):292-6. 
Krzywda EA, Andris DA. Twenty-five years of advances in vascular access: bridging research to clinical practice. SAGE J; 2005.

Lapalu J, Losser MR, Albert O, Levert H, Villiers S, Faure P, Douard MC. Totally implantable port management: impact of positive pressure during needle withdrawal on catheter tip occlusion (an experimental study). J Vasc Access. 2010;11:46-51.

Logan R. Neutral displacement intravenous connectors: evaluating new technology; 2013.

Lopez-Britz E. Garcia R, Cabello JB. Heparin versus $0.9 \%$ sodium chloride intermittent flushing for prevention of occlusion in central venous catheters in adults. Cochrane quality and production topics; 2014.

Losert H, Prokesch R, Grabenwoger M, et al. Inadvertent transpericardial insertion of a central venous line with cardiac tamponade failure of preventative practices. Intensive Care Med. 2000;26:1147-50.

Loveday HP, Wilson JA, Pratt RJ, Golsorkhi M, Tingle A, Bak A, Browne J, Prieto J, Wilcox M. EPIC3: national evidence-based guidelines for preventing healthcareassociated infections in NHS hospitals in England. J Hosp Infect. 2014;S86(1):S1-S70.

Lyons MG. An evidentiary review of flushing protocols in home care patients with peripherally inserted central catheters. Infusion. 2012;18:32-44.

Macklin D. The impact of IV connectors on clinical practice and patient outcomes. J Assoc Vasc Access. 2014;15(3):139. https://doi.org/10.2309/java.15-3-4.

Markota I, Markota D, Tomic M. Measuring of the heparin leakage into the circulation from central venous catheters- an in vivo study. Nephrol Dial Transplant. 2009;24:1550-3.

Marschall J, Mermel LA, Fakih M, Hadaway L, Kallen A, O'Grady N, Pettis A, Rupp ME, Sandora T, Maragakis LL, Yokoe D. Strategies to prevent central line-associated bloodstream infections in acute care hospitals: 2014 update. Infect Contr Hosp Epidemiol. 2014;35(7):753-71. http://digitalcommons.wustl.edu/ open_access_pubs/3453

Mitchell MD, Anderson BJ, Williams K, Umscheid CA. Heparin flushing and other interventions to maintain patency of central venous catheters: a systematic review. J Adv Nurs. 2009;65(10):2007-21.

Miyagaki H, Nakajima K, Hara J, Yamasaki M, Kurokawa Y, Miyata H, Takiguchi S, Fujiwara Y, Mori M, Doki Y. Performance comparison of peripherally inserted central venous catheters in gastrointestinal surgery: a randomized controlled trial. Clin Nutr. 2012;31(1):48-52.

Moureau NL. Safe patient care when using vascular access devices. Br J Nurs. 2013;22(1):S14-21.

Moureau NL, Flynn J. Disinfection of needleless connector hubs: clinical evidence systematic review. Nurs Res Pract. 2015;2015:1-20.

Muslimani AA, Ricaurte B, Daw HA. Immune heparininduced thrombocytopenia resulting from preced- ing exposure to heparin flushes. Am J Hematol. 2007;82(7):652-5.

National Institute for Health Care Excellence (NICE). Intravenous fluid therapy in adults in hospital. NICE CS174. 2017. https://www.nice.org.uk/guidance/cg174.

NICE. Clinical Guideline 139-Healthcare-associated infections: prevention and control in primary and community care. 2012. https://www.nice.org.uk/ guidance/cg139/evidence/control-full-guidelinepdf-185186701. Accessed Sept 2017.

NICE. The 3M Tegaderm CHG IV securement dressing for central venous and arterial catheter insertion sites. 2015. https://www.nice.org.uk/guidance/mtg25. Accessed Sept 2017.

O'Grady N, Alexander M, Burns L, Dellinger E, Garland J, Heard S, et al. Centers for Disease Control Guidelines for the prevention of intravascular catheter-related infections. Clin Infect Dis. 2011;52(9):e162-93.

Ong CK, Venkatesh SK. Prospective randomised comparative evaluation of proximal valve polyurethane and distal valve silicone peripherally inserted central catheters. J Vasc Interv Radiol. 2010;21(8):1191-6.

Pereira $S$, et al. When one port does not return blood: two case reports of rare causes for misplaced central venous catheters. Soc Anaesthesiol. 2013;66(1):78-81.

Pikwer A, Baath L, et al. The incidence and risk of central venous catheter malpositioning: a prospective cohort study in 1619 patients. Anaeth Intensive Care. 2008;36(1):30-7.

Pittiruti M, Hamilton H, Biffi R, et al. ESPEN guidelines on parenteral nutrition: central venous catheters (access, care, diagnosis and therapy of complications). Clin Nutr. 2009;28:365-77.

Polaschegg H-D. Loss of catheter locking solution caused by fluid density. ASAIO J. 2005;51(3):230-5.

Polaschegg H-D, Shaht C. Overspill of catheter locking solution: safety and efficacy aspects. ASAIO J. 2003;49(6):713-5.

Ponec D, Irwin D, Haire W, Hill P, Li X, McCluskey E. Recombinant tissue plasminogen activator (Alteplase) for restoration of flow in occluded central venous access devices: a double-blind placebo-controlled trial-the cardiovascular thrombolytic to open occluded lines (COOL) efficacy trial. JVIR. 2001;12(8):951-5. https://doi.org/10.1016/ S1051-0443(07)61575-9.

Randolph AD, Cook DJ, Gonzales CA, Andrew M. Benefit of heparin in peripheral venous and arterial catheters: systematic review and metaanalysis of randomised controlled trials. Br Med J. 1998;316(7136):969-75.

Rolden CJ, Paniagua L. Central venous catheter intravascular malpositioning: causes, prevention, diagnosis and correction. Weston J Emerg Med. 2015;16(5):658-64.

Royal College of Nursing. Standards for infusion nursing. 4th ed. London: Royal Collage of Nursing; 2016. 
Royon L, Durussel JJ, Merckx J, et al. The fouling and cleaning of venous catheters: a possible optimisation of the process using intermittent flushing. Chem Eng Res Des. 2012;90(6):803-7.

Ryder M. Needlefree connectors. Canadian Vascular Access Association presentation. 2010. https://cvaa. info/en/news-events/conference-2011/speakers-presentations-2010/itemid/214. Accessed 4 Aug 2019.

Sauerland C, Engelking C, Wickham R, Corbi D. Vesicant extravasation part 1: mechanisms, pathogenisis and nursing care to reduce risk. Oncol Nurs Forum. 2005;33(6):1134-42.

Semba CP, Deitcher SR, Li X, Resnansky L, Tu T, McCluskey ER, Investigators C. Treatment of occluded central venous catheters with alteplase: results in 1,064 patients. J Vasc Interv Radiol. 2002;13(12):1199-205.

Shallom ME, Prentice D, Sona C. Heparin or $0.9 \%$ sodium chloride to maintain central venous catheter patency: a randomised trial. Crit Care Med. 2012;40(6):1820-6.

Sona C, Prentice D, Schallom L. National survey of central venous catheter flushing in the intensive care unit. Crit Care Nurse. 2012;32(1):e12-9.

Sungur M, Eryuksel E, Yavas S, et al. Exit of catheter lock solutions from double lumen acute haemodialysis catheters an in vitro study. Nephrol Dial Transplant. 2007;22:3533-7.

Vigier JP, Merckx J, Coquin JY. The use of a hydrodynamic bench for experimental simulation of flushing venous catheters: impact of the technique. ITBMRBM. 2005;26(2):147-9.

Open Access This chapter is licensed under the terms of the Creative Commons Attribution 4.0 International License (http://creativecommons.org/licenses/by/4.0/), which permits use, sharing, adaptation, distribution and reproduction in any medium or format, as long as you give appropriate credit to the original author(s) and the source, provide a link to the Creative Commons license and indicate if changes were made.

The images or other third party material in this chapter are included in the chapter's Creative Commons license, unless indicated otherwise in a credit line to the material. If material is not included in the chapter's Creative Commons license and your intended use is not permitted by statutory regulation or exceeds the permitted use, you will need to obtain permission directly from the copyright holder.

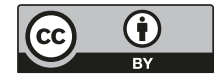

